\title{
ESPACIALIZAÇÃO VERTICAL E HORIZONTAL DOS INDICADORES DE QUALIDADE PARA UM LATOSSOLO VERMELHO CULTIVADO COM CITROS ${ }^{(1)}$
}

\author{
Jonez Fidalski ${ }^{(2)}$, Cássio Antonio \\ Tormena $^{(3)}$ \& Carlos Alberto Scapim ${ }^{(3)}$
}

\begin{abstract}
RESUMO
O objetivo deste trabalho foi verificar a forma de espacialização vertical e horizontal dos indicadores de qualidade química, física e hídrica de um Latossolo Vermelho distrófico textura média, cultivado com citros. $O$ pomar de laranjeira Valência sobre limoeiro Cravo foi plantado em 1995, em Alto Paraná, região noroeste do Paraná. Em agosto de 2002, coletaram-se amostras deformadas e indeformadas de solo para realizar determinações químicas, físicas e hídricas. A amostragem foi feita em 24 transeções perpendiculares aos troncos das laranjeiras, em duas profundidades $(0-0,20$ e $0,20-0,40 \mathrm{~m}$ ) e em três posições (projeção da copa da laranjeira, rodado da entrelinha e centro da entrelinha). Os indicadores avaliados foram submetidos às análises multivariadas, por meio dos componentes principais, e agrupados pelo método de Tocher. Os resultados demonstraram que a qualidade do solo apresentou espacialização heterogênea entre os indicadores de qualidade física, química e hídrica do solo, resultante das ações de manejo do pomar de laranjeira. A integração dos indicadores de qualidade física, química e hídrica do solo caracterizou a espacialização vertical da qualidade do solo $(0-0,40 \mathrm{~m}) \mathrm{na}$ projeção da copa da laranjeira e a espacialização vertical e horizontal (0-0,20 e $0,20-0,40 \mathrm{~m}$ ) no rodado da entrelinha e centro da entrelinha. No rodado da entrelinha $(0-0,20 \mathrm{~m})$ ocorreu a maior restrição física e hídrica associada à melhor condição química do solo para as laranjeiras.
\end{abstract}

Termos de indexação: compactação do solo, água no solo, densidade do solo, manejo do solo, acidez, cálcio, calagem.

\footnotetext{
(1) Trabalho recebido para publicação em fevereiro de 2006 e aprovado em dezembro de 2006.

(2) Pesquisador do Instituto Agronômico do Paraná - IAPAR. Caixa Postal 564, CEP 87701-970 Paranavaí (PR). E-mail: fidalski@iapar.br

(3) Professor Adjunto do Departamento de Agronomia da Universidade Estadual de Maringá - UEM. Av. Colombo, 5790, CEP 87020900 Maringá (PR). E-mail: catormena@uem.br, cascapim@uem.br. Bolsista do CNPq.
} 


\title{
SUMMARY: VERTICALAND HORIZONTAL SPATIALIZATION OF QUALITY INDICATORS OF A TYPIC HAPLORTOX UNDER CITRUS
}

\begin{abstract}
The objective of this report was to verify the form of vertical and horizontal spatialization of chemical, physical and water quality indicators of a Typic Haplortox cultivated with citrus. The 'Valencia' orange grove on 'Rangpur' lime was planted in 1995, in the county of Alto Paraná, northwestern Paraná, Brazil. In August 2002, undisturbed and disturbed samples were collected for chemical, physical and water analysis. Twentyfour transects were sampled perpendicular to the tree trunk, in two layers $(0-0.20$ and 0.20-0.40 m depth) and three sampling positions (tree crown projection, underneath the wheel track and between the wheel tracks). The indicators measured were submitted to multivariate analysis by main components and were grouped by the Tocher method. The soil quality demonstrated heterogeneous spatialization among the soil physical, chemical and water soil quality indicators, as a result of the management actions on the plantation. The integration of the soil indicators of physical, chemical and water quality characterized a vertical spatialization $(0-0.40 \mathrm{~m})$ in the tree crown projection and vertical and horizontal spatialization $(0-0.20$ and $0.20-0.40 \mathrm{~m})$ underneath and between the wheel tracks. Underneath the wheel tracks $(0-0.20 \mathrm{~m})$ the physical and water restrictions were strongest while soil chemical conditions for orange trees were the best.
\end{abstract}

Index terms: soil compaction, soil water, soil bulk density, soil management, acidity, calcium, liming.

\section{INTRODUÇÃO}

Progressivamente, vem sendo incluída a amostragem de solo no local em que ocorre a sobreposição do tráfego de máquinas na entrelinha, identificada pela presença de sulcos decorrentes da deformação do solo, denominada rodado da entrelinha. Esse local está espacialmente localizado entre o limite da projeção da copa das plantas, próximo da faixa de adubação, e o centro da entrelinha nos pomares em produção de videira, macieira e laranjeira (Ferrero et al., 2005; Draghi et al., 2005; Lima et al., 2005).

A amostragem de solo na região de sobreposição do tráfego nas entrelinhas tem a finalidade de identificar possíveis restrições químicas, físicas e hídricas ao desenvolvimento das laranjeiras, a exemplo dos estudos realizados por Fidalski (2004), Draghi et al. (2005), Ferrero et al. (2005) e Lima et al. (2005). As propriedades físicas do solo comumente avaliadas em pomares de laranjeira são: densidade do solo, porosidade, resistência do solo à penetração, teor de água do solo, taxa de infiltração de água e curvas de retenção de água (Cintra et al., 1983; Abercrombie \& Plessis, 1995; Sanches et al., 1999; Fidalski, 2004; Souza et al., 2004; Lima et al., 2005).

A produção da laranjeira Valência sobre o portaenxerto limoeiro Cravo é dependente do preparo convencional do solo em área total, enquanto outros cinco porta-enxertos podem ser plantados sem o preparo do solo na entrelinha de $2 \mathrm{~m}$ de largura (preparo do solo em faixa), em áreas de pastagem com a gramínea mato-grosso ou batatais (Paspalum notatum), mantendo-se essa gramínea remanescente na entrelinha do pomar de $5 \mathrm{~m}$ de largura (Auler et al., 2004). A compactação em citros pode ser identificada pelo método do perfil cultural (Tavares Filho et al., 1999), pela densidade do solo (Sanches et al., 1999), pela porosidade do solo (Soares et al., 2005) e pela resistência do solo à penetração (Abercrombie $\&$ Plessis, 1995). O método do perfil cultural revelou compactação vertical na camada de $0-0,30 \mathrm{~m}$ sob o rodado da entrelinha e horizontal com tendência à compactação na camada de $0,10-0,30 \mathrm{~m}$ sob a projeção da copa das plantas e o centro da entrelinha (Tavares Filho et al., 1999) em um solo argiloso cultivado com tangerineira Poncã (Neves et al., 1998). Nesse estudo, a compactação do solo no rodado da entrelinha foi atribuída ao tráfego de máquinas por ocasião das operações de roçagem e colheita da produção. A alteração da estrutura do solo (porosidade e densidade do solo) em subsuperfície foi verificada em pomar de laranjeira submetido ao cultivo convencional e intensivo do solo durante vários anos, de modo mais acentuado em solo arenoso (Soares et al., 2005). Por sua vez, outros estudos em pomar de laranjeira não identificaram compactação do solo nas camadas superficiais e subsuperficiais (Sanches et al., 1999), tampouco entre as posições de amostragem relativas ao centro da entrelinha, ao rodado da entrelinha e à projeção da copa da laranjeira (Bordin et al., 2005; Lima et al., 2005).

O crescimento das raízes de citros é dependente da neutralização do $\mathrm{Al}^{3+}$ e do aumento da concentração de $\mathrm{Ca}^{2+}$ no solo (Pavan \& Jacomino, 1998). Em pomares de laranjeira em produção são recomendadas as amostragens de solo na faixa adubada próximo à 
projeção da copa das plantas e no centro da entrelinha, estratificadas em camadas de $0-0,20 \mathrm{~m}$, com a finalidade de recomendação de adubação e calagem, e na camada de 0,20-0,40 m, para diagnosticar barreiras químicas, ou seja, deficiência de $\mathrm{Ca}^{2+}$ ou excesso de $\mathrm{Al}^{3+}$ (Malavolta \& Violante Netto, 1989; Grupo Paulista de Adubação e Calagem para Citros, 1994). A sobreposição das curvas de resposta da produção de frutos de laranjeira Valência com a saturação por bases na profundidade de 0-0,20 m, obtidas por Quaggio et al. (1992) entre as posições de amostragem de solo na faixa de adubação, na projeção da copa das plantas e no centro da entrelinha, permite inferir a espacialização horizontal da saturação por bases. Com bases nesses resultados, Quaggio (1996) concluiu que a coleta de amostras de terra para a citricultura, para ser mais representativa do ambiente radicular dos citros, deveria ser feita conjuntamente, coletando-se amostras de solo na projeção da copa e também distantes dela cerca de 1,0 a $1,5 \mathrm{~m}$, em direção ao meio centro da entrelinha.

O consumo de água pela laranjeira Valência ocorre na camada de $0-0,60 \mathrm{~m}$, avaliado sob a projeção da copa das plantas por Cruz et al. (2005), atribuído ao maior volume de raízes ativas nessa camada, verificado em diferentes porta-enxertos de citros por Neves et al. (2004). Em solos com severas limitações físicas de porosidade, como os dos Tabuleiros Costeiros, com camadas coesas subsuperficiais, houve aumento de água disponível no solo após a subsolagem na profundidade de $0,50 \mathrm{~m}$ na entrelinha do pomar, distante 2,00 m do tronco das laranjeiras na entrelinha (Souza et al., 2004). As relações físicas e hídricas do solo apresentam espacialização horizontal entre as posições de amostragem de solo rodado da entrelinha e centro da entrelinha, dependentes das plantas de cobertura permanente (Fidalski, 2004; Fidalski et al., 2006). Nesses estudos foram verificadas melhores relações químicas, físicas e hídricas do solo com os parâmetros fisiológicos das folhas das laranjeiras (taxa de fotossíntese, condutância estomática e potencial da água) em ordem decrescente das vegetações permanentes: gramínea (Paspalum notatum), leguminosa (Arachis pintoi) e espontânea. Contrariamente, Morgan et al. (2006) constataram descontinuidade horizontal entre a projeção da copa de laranjeiras e a entrelinha com predominância dessa gramínea, atribuída à depleção da água do solo na camada de 0$0,10 \mathrm{~m}$, que apresentou maior densidade de raízes.

De modo geral, os estudos que quantificam a qualidade do solo em pomares de laranjeira apresentam inúmeras variáveis químicas, físicas e hídricas, as quais são descritas por meio de análises estatísticas univariadas, possivelmente comprometendo as interpretações e as conclusões destes, por não ser explorada a existência ou não da dependência entre as variáveis analisadas. A análise multivariada por meio de componentes principais não tem sido utilizada para discriminar, vertical e horizontalmente, a qualidade do solo em pomares de laranjeira. Contudo, observase a sua utilização para agrupar as alterações químicas do solo nos sistemas de manejo orgânico e convencional de cafeeiro (Theodoro et al., 2003).

O objetivo deste trabalho foi verificar a forma de espacialização vertical e horizontal dos indicadores de qualidade química, física e hídrica de um Latossolo Vermelho distrófico cultivado com citros.

\section{MATERIAL E MÉTODOS}

O estudo foi realizado em um pomar comercial de laranjeira Valência (Citrus sinensis) enxertada sobre o limoeiro Cravo (Citrus limonia), no município de Alto Paraná, região noroeste do Paraná, localizado nas proximidades das coordenadas $23^{\circ} 5^{\prime} \mathrm{S}, 52^{\circ} 26^{\prime} \mathrm{W}$ e altitude de $480 \mathrm{~m}$. O clima da região é subtropical (Cfa), segundo a classificação de Köppen, sem estação seca definida e concentração de chuvas no verão, com precipitação anual de $1.400 \mathrm{~mm}$ (IAPAR, 2000). Para caracterização da classe de solo foi aberta uma trincheira de 1,5 $\mathrm{m}$ de profundidade, seguida da coleta de amostras de solos para as análises granulométricas (Embrapa, 1997). O solo foi identificado como Latossolo Vermelho distrófico textura média A moderado relevo suave-ondulado (Embrapa, 1999), desenvolvido a partir do arenito da Formação Caiuá, cuja análise granulométrica é apresentada no quadro 1.

Quadro 1. Teores de argila, silte e areia do perfil do Latossolo Vermelho distrófico textura média A moderado relevo suave-ondulado

\begin{tabular}{cccc}
\hline Profundidade & Argila & Silte & Areia \\
\hline m & & $\mathrm{kg}^{-1}$ \\
$0-0,20$ & 180 & 40 & 780 \\
$0,20-0,40$ & 180 & 40 & 20 \\
$0,40-0,60$ & 180 & 20 & 780 \\
$0,60-0,80$ & 210 & 30 & 770 \\
$0,80-1,00$ & 200 & 30 & 770 \\
$1,00-1,20$ & 210 & 40 & 760 \\
$1,20-1,40$ & 180 & & 780 \\
\hline
\end{tabular}


O histórico de uso desse solo consistiu do desmatamento na década de 50, seguido do plantio e cultivo de café até a década de 70 . A partir de 1975 , foi implantada a pastagem (Panicum maximum), posteriormente substituída por Brachiaria decumbens, culminando com a degradação do seu potencial produtivo na década de 90 . Posteriormente, iniciou-se a recuperação da pastagem, que foi realizada com dois cultivos de mandioca de dois ciclos (18 meses), utilizando-se o preparo convencional do solo e a incorporação de $2 \mathrm{t}$ ha ${ }^{-1}$ de calcário dolomítico. Em 1995, antes de ser concluído o processo de recuperação da pastagem, foi implantado um pomar de laranjeira no espaçamento de $7,0 \times 3,5 \mathrm{~m}$.

O manejo nutricional do pomar de laranjeira baseou-se na aplicação de aproximadamente $1 \mathrm{t} \mathrm{ha}^{-1}$ de fertilizante NPK (20-05-20) próximo ao limite externo da projeção da copa da laranjeira. A última correção da acidez do solo foi feita em 2000 para elevar a saturação por bases a $70 \%$, à base de $1,5 \mathrm{t} \mathrm{ha}^{-1} \mathrm{de}$ calcário dolomítico, distribuído em toda a área do pomar com um distribuidor mecânico do tipo pendular, sem incorporação mecânica.

As plantas nas linhas das laranjeiras foram controladas por meio de aplicações de herbicida dessecante (Glyphosate), conforme a necessidade de controle. Nas entrelinhas, o controle foi realizado anualmente com duas a três roçadas mecânicas. Para os tratos fitossanitários, adubação, calagem, controle da vegetação e colheita de frutos foi utilizado um pulverizador com capacidade de $2.000 \mathrm{~L} \mathrm{e} \mathrm{um} \mathrm{trator}$ de pneu, respectivamente com massa aproximada de $1 \mathrm{e} 4 \mathrm{t}$. No momento da amostragem, as plantas apresentavam bom estado fitossanitário e as produções nas últimas colheitas variaram de duas a quatro caixas de frutos de $40,8 \mathrm{~kg}$ por planta.

A amostragem de solo foi realizada em agosto de 2002, em uma área homogênea de 1,5 ha no centro de um talhão de 7,0 ha, selecionando-se, aleatoriamente, 24 transeções perpendiculares ao tronco das laranjeiras. Em cada uma das laranjeiras, foram definidas três posições de amostragem de solo: projeção da copa da laranjeira - no limite da projeção da copa da planta, coincidente com a faixa de adubação, distante $1,75 \mathrm{~m}$ do tronco da planta; rodado da entrelinha - identificado pela presença de sulco resultante da sobreposição dos pneus do trator na entrelinha do pomar, distante $2,25 \mathrm{~m}$ do tronco da planta; e centro da entrelinha - no centro da entrelinha, distante $3,50 \mathrm{~m}$ do tronco da planta, sem sobreposição do tráfego do trator após a fase de formação do pomar.

Nas três posições de amostragem foram coletadas amostras indeformadas de solo no centro das camadas de $0-0,20$ e $0,20-0,40 \mathrm{~m}$ de profundidade, utilizandose anéis metálicos com volume de $100 \mathrm{~cm}^{3}$. Adjacentes a esses pontos, inferior a $0,50 \mathrm{~m}$ de distância, foram coletadas amostras deformadas de solo nas camadas de $0-0,10,0,10-0,20,0,20-0,30$ e $0,30-0,40 \mathrm{~m}$ de profundidade, com um trado tipo sonda, para as determinações dos indicadores de qualidade química do solo, sendo cada uma delas composta de quatro subamostras. Para os indicadores de qualidade química do solo, as amostras foram agrupadas em duas camadas similares às dos indicadores de qualidade física e hídrica $(0-0,20$ e $0,20-0,40 \mathrm{~m})$, obtendo-se a média dos valores dos indicadores químicos medidos nas amostras de solo.

As amostras indeformadas foram saturadas em bandeja com água e submetidas aos potenciais mátricos de - $-0,001,-0,002,-0,003,-0,004,-0,005$ e - $-0,006 \mathrm{MPa}$ em mesa de tensão (Romano et al., 2002) e de -0,010, $-0,033,-0,070,-0,100$ e $-1,500 \mathrm{MPa}$ em placas porosas (Dane \& Hopmans, 2002). Após atingir o equilíbrio hidráulico, as amostras foram pesadas e, em seguida, determinou-se a resistência do solo à penetração (RP) em um penetrômetro eletrônico descrito por Tormena et al. (1998), com as amostras de solo apresentando teor de água entre 0,09 e $0,27 \mathrm{~m}^{3} \mathrm{~m}^{-3}$, dependendo da variação dos potenciais mátricos aplicados a elas. Em seguida, as amostras de solo foram secas em estufa a $\pm 105{ }^{\circ} \mathrm{C}$ por $24 \mathrm{~h}$, para determinação do teor de água ( $\theta$ ) e da densidade do solo (Grossman \& Reinsch, 2002). A textura e o fracionamento da areia (areia fina: $0,05-0,20 \mathrm{~mm}$ e areia grossa: $0,20-2,00 \mathrm{~mm}$ ), o teor de argila dispersa e o grau de floculação foram determinados conforme Embrapa (1997), utilizandose as amostras de solo deformadas.

Os indicadores de qualidade hídrica do solo foram definidos a partir das características de retenção de água do solo, calculando a relação entre o teor de água retido em um determinado potencial mátrico e a porosidade total do solo, ou seja, a saturação relativa do solo. Dessa forma, foi calculada a saturação relativa nos potenciais mátricos de $-0,001$ a - $-0,010 \mathrm{MPa}$, a qual indica a proporção de água retida do solo ou, alternativamente, a proporção do espaço poroso com ar em cada potencial mátrico. No potencial mátrico de -0,006 MPa, definiu-se o indicador de qualidade física do solo $\theta c c / \mathrm{Pt}$, proposto por Reynolds et al. (2002), em que $\theta c c$ corresponde ao teor de água retido nesse potencial mátrico equivalente à capacidade de campo (Reichardt, 1988) e Pt corresponde à porosidade total do solo, a qual foi calculada como: $\{\mathrm{Pt}=1$ - [(Densidade do solo)/(Densidade de partículas do solo)]\}, utilizandose o valor médio de $2,62 \mathrm{Mg} \mathrm{m}^{-3}$ para a densidade de partículas do solo, determinado por Fidalski (2004).

As determinações dos indicadores de qualidade química nas amostras deformadas de solo foram realizadas de acordo com o método proposto pela Embrapa (1997): pH, em $\mathrm{CaCl}_{2}(0,01 \mathrm{M}) ; \mathrm{Ca}^{2+}, \mathrm{Mg}^{2+} \mathrm{e}$ $\mathrm{Al}^{3+}$, em espectrofotômetro de absorção atômica após extração com $\mathrm{KCl}(1 \mathrm{M})$; P disponível e $\mathrm{K}^{+}$, extraídos por meio da solução Mehlich-1; e o carbono orgânico, determinado pelo método Walkley-Black. Com os resultados analíticos de $\mathrm{H}+\mathrm{Al}, \mathrm{Ca}^{2+}, \mathrm{Mg}^{2+}$ e $\mathrm{K}^{+}$ estimaram-se a soma de bases (SB), a capacidade de troca de cátions (CTC) e a saturação por bases (V). 
Antes de submeter os dados às análises multivariadas, foi verificado se os indicadores de qualidade química, física e hídrica do solo atendiam aos pressupostos básicos de normalidade dos resíduos e homocedasticidade das variâncias, utilizando os testes de normalidade dos resíduos (teste de ShapiroWilk; $\mathrm{P}>0,01$ ) e de homocedasticidade das variâncias (teste de Levene; $\mathrm{P}>0,01$ ), por meio do programa estatístico SAS (SAS, 2001). Essas análises exploratórias dos dados indicaram a necessidade de transformação logarítmica dos indicadores $\mathrm{P}, \mathrm{H}+\mathrm{Al}$, carbono orgânico, RP (valores médios obtidos em 12 potenciais mátricos), $\theta / \mathrm{Pt}$ no potencial de $-0,010 \mathrm{MPa}$ e arco-seno da raiz de $\theta / \mathrm{Pt}$ nos potenciais mátricos de $-0,001$ e $-0,004 \mathrm{MPa}$.

As análises multivariadas foram realizadas utilizando-se aos indicadores de qualidade do solo que atenderam os pressupostos básicos, resultando em seis indicadores de qualidade química (carbono orgânico, $\mathrm{H}+\mathrm{Al}, \mathrm{Ca}^{2+}$, SB, CTC e P); dez indicadores de qualidade física (argila total, argila dispersa em água, areia total, areia fina, areia grossa, microporosidade, macroporosidade, porosidade total, densidade do solo e resistência do solo à penetração); e cinco indicadores de qualidade hídrica $(\theta / \mathrm{Pt}$ nos potenciais mátricos de $-0,001,-0,004,-0,005$ e $-0,010 \mathrm{MPa}$ e $\theta \mathrm{cc} / \mathrm{Pt}$ no potencial mátrico de -0,006 $\mathrm{MPa}$ ).

As análises multivariadas basearam-se em análises dos componentes principais, que consistem em transformar um conjunto de variáveis utilizando uma combinação linear com dimensões equivalentes, por meio da redução da dimensionalidade do conjunto de variáveis, com menor perda possível de informação, em dois eixos ortogonais não-correlacionados ( $\mathrm{C} 1$ e C2). Para isso, essas duas variáveis devem envolver no mínimo $80 \%$ da variação total, permitindo, graficamente, a representação da posição e camada de solo entre o primeiro eixo na abscissa (C1) e o segundo eixo na ordenada (C2), conforme indicações de Cruz et al. (2004). Foi adotado o método de agrupamento via ligação média entre grupo (UPMGA) com o procedimento da distância euclidiana média. O agrupamento foi obtido pelo método Tocher, conforme Cruz et al. (2004). Nas análises estatísticas multivariadas foi utilizado o programa estatístico GENES (Cruz, 2001).

\section{RESULTADOS E DISCUSSÃO}

Os indicadores químicos de qualidade avaliados corresponderam à fertilidade dos solos em pomares de laranjeira, conferida pela maior acidez $(\mathrm{pH} \mathrm{e} \mathrm{H}+\mathrm{Al})$ e pelos maiores teores de $\mathrm{P}$ devido à aplicação localizada dos fertilizantes na projeção da copa da laranjeira (Figura 1). Resultados similares foram obtidos, nesse solo, por Fidalski \& Auler (1997), Fidalski et al. (1999) e Fidalski \& Stenzel (2006).
Os indicadores de qualidade química mostraram que a fertilidade do solo está concentrada na camada superficial de $0-0,20 \mathrm{~m}$, à exceção do $\mathrm{K}^{+}$, que apresentou maiores teores na projeção da copa da laranjeira, $0,17 \mathrm{cmol}_{\mathrm{c}} \mathrm{dm}^{-3}$, homogêneos nas camadas de 0-0,20 e 0,20-0,40 m (Figura 1) e próximos ao limite crítico de $0,20 \mathrm{cmol}_{\mathrm{c}} \mathrm{dm}^{-3}$ (Quaggio et al., 1998).

Contrariamente, maiores teores de $\mathrm{Ca}^{2+}$ foram observados no rodado da entrelinha $(0-0,20$ e 0,20 $0,40 \mathrm{~m}$ ), e, pela predominância desse cátion no complexo de troca, verificam-se maiores valores de SB, CTC e V (Figura 1). Por sua vez, os teores de $\mathrm{Al}^{3+}$ na projeção da copa da laranjeira $(0,20-0,40 \mathrm{~m})$ apresentaram valores máximos de $0,60 \mathrm{cmol}_{\mathrm{c}} \mathrm{dm}^{-3}$, correspondendo à saturação por alumínio de $35 \%$. Nas demais camadas e posições de amostragem de solo, os teores e a saturação por $\mathrm{Al}^{+3}$ foram, respectivamente, menores que $0,23 \mathrm{cmol}_{\mathrm{c}} \mathrm{dm}^{-3} \mathrm{e} 12 \%$. Tendo em vista esses índices, o pomar não apresentou impedimentos químicos para o desenvolvimento das raízes do portaenxerto limoeiro Cravo, considerando-se os valores mínimos de $\mathrm{pH}(5,0)$ e saturação por bases $(\mathrm{V}=30 \%)$ na camada de $0,20-0,40 \mathrm{~m}$ (Figura 1). De acordo com Quaggio et al. (1992) e Quaggio (1996), o valor de $30 \%$ da saturação por bases (V) na faixa de adubação corresponde ao valor crítico para a produção de laranjeira Valência na camada de $0-0,20 \mathrm{~m}$. A eficiência da calagem superficial utilizada nesse pomar é constatada pelos valores de $\mathrm{V}$ de 53 e $57 \%$ na entrelinha (centro da entrelinha e rodado da entrelinha), semelhante ao valor máximo de $63 \%$ obtido experimentalmente nesse solo por Fidalski \& Tormena (2005). Os indicadores de qualidade química apresentados na figura 1 descartam a necessidade da utilização de gesso agrícola ou de incorporação mecânica de calcário para correção da acidez subsuperficial.

Os indicadores de qualidade química do solo se agruparam estatisticamente em três grupos, com os autovalores dos dois primeiros componentes principais explicando $89 \%$ da variação total (Figura 2), atendendo ao critério mínimo de $80 \%$ sugerido por Cruz et al. (2004). O grupo 1 foi constituído pela projeção da copa da laranjeira, pelo rodado da entrelinha e pelo centro da entrelinha $(0,20-0,40 \mathrm{~m})$; o grupo 2, pelo rodado da entrelinha e centro da entrelinha (0-0,20 m); e o grupo 3, pela projeção da copa da laranjeira $(0-0,20 \mathrm{~m})$. As diferenças entre os três grupos confirmam a descontinuidade da qualidade química do solo na camada de $0-0,20 \mathrm{~m}$ entre a projeção da copa da laranjeira e a entrelinha (rodado da entrelinha e centro da entrelinha), resultante do manejo localizado das adubações (Fidalski \& Auler, 1997). A distribuição espacial dos indicadores da qualidade química do solo sugere um gradiente horizontal de fertilidade entre as camadas de $0-0,20 \mathrm{~m}$ e 0,20-0,40 m. Esses resultados indicam que o manejo das adubações químicas não está alterando a qualidade química do solo na camada de $0,20-0,40 \mathrm{~m}$, restrita 

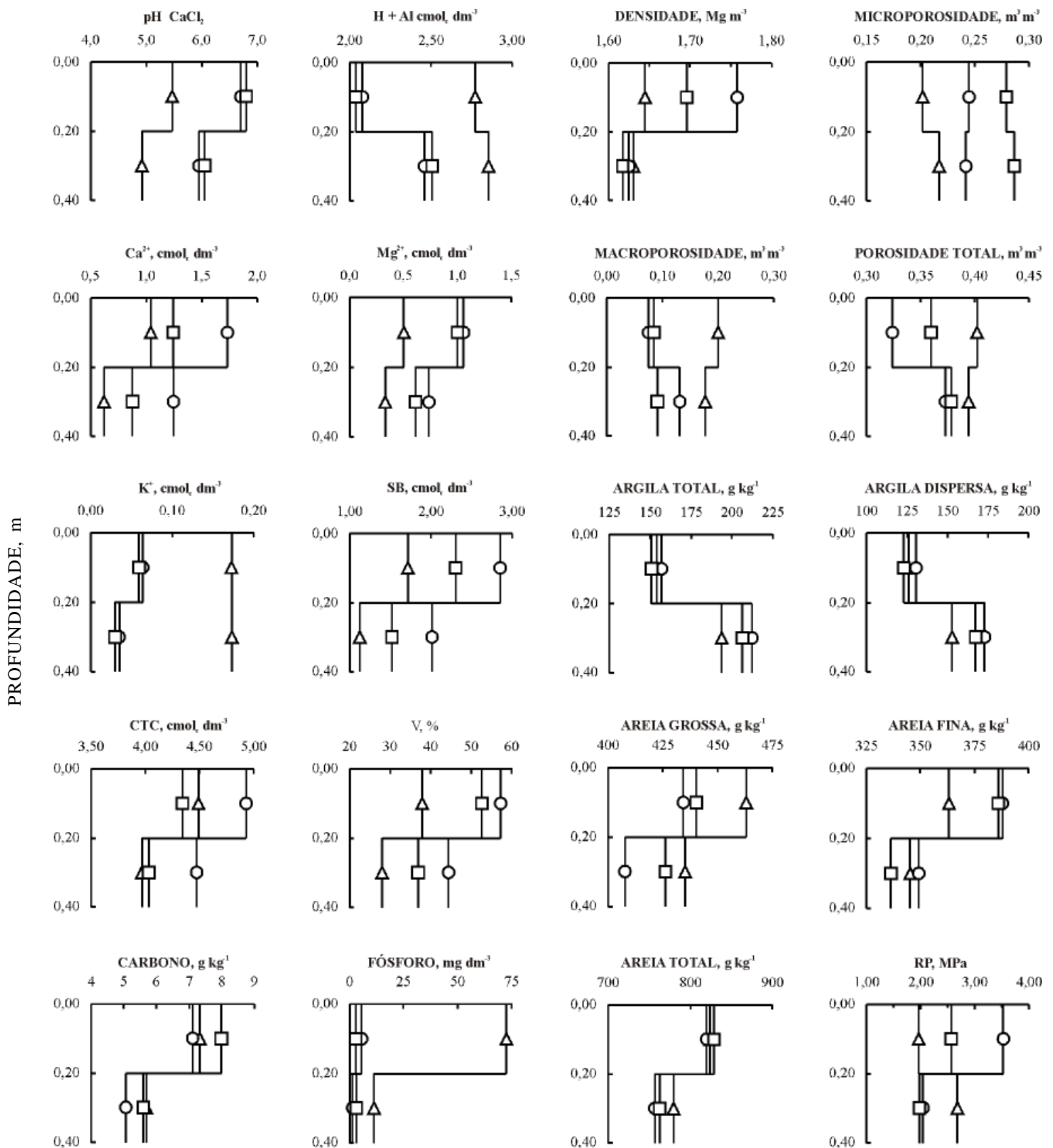

Figura 1. Indicadores de qualidade química e física do Latossolo Vermelho distrófico cultivado com laranjeira Valência, na projeção da copa da laranjeira $(\triangle)$, no rodado da entrelinha $(O)$ e no centro da entrelinha ( $\square$ ), para as camadas de $0-0,20$ e $0,20-0,40 \mathrm{~m}$ de profundidade.

apenas à camada de $0-0,20 \mathrm{~m}$ na projeção da copa da laranjeira (Figura 1). Os resultados das análises multivariadas vêm confirmar a necessidade da amostragem de solo separada por posição de amostragem relativa à projeção da copa da laranjeira e à entrelinha na camada de 0-0,20 m (Malavolta \& Violante Netto, 1989; Grupo Paulista de Adubação e Calagem para Citros, 1994), enquanto na camada de 0,20-0,40 m pode ser coletada amostra de solo conjuntamente nas três posições de amostragem.
A análise granulométrica confirmou a textura média do solo, por ter apresentado teores de argila de 151 a $212 \mathrm{~g} \mathrm{~kg}^{-1}$ (Figura 1), com gradiente textural de 1,34 entre as camadas de 0-0,20 e 0,20-0,40 m. O menor grau de floculação do solo (16\%) foi constatado na camada de $0-0,20 \mathrm{~m}$ do rodado da entrelinha, inferior às demais camadas e posições de amostragem de solo. Esses resultados são semelhantes aos descritos por Cardoso et al. (1992) para a mesma classe de solo cultivado com cafeeiros, distinguindo-se das pastagens 

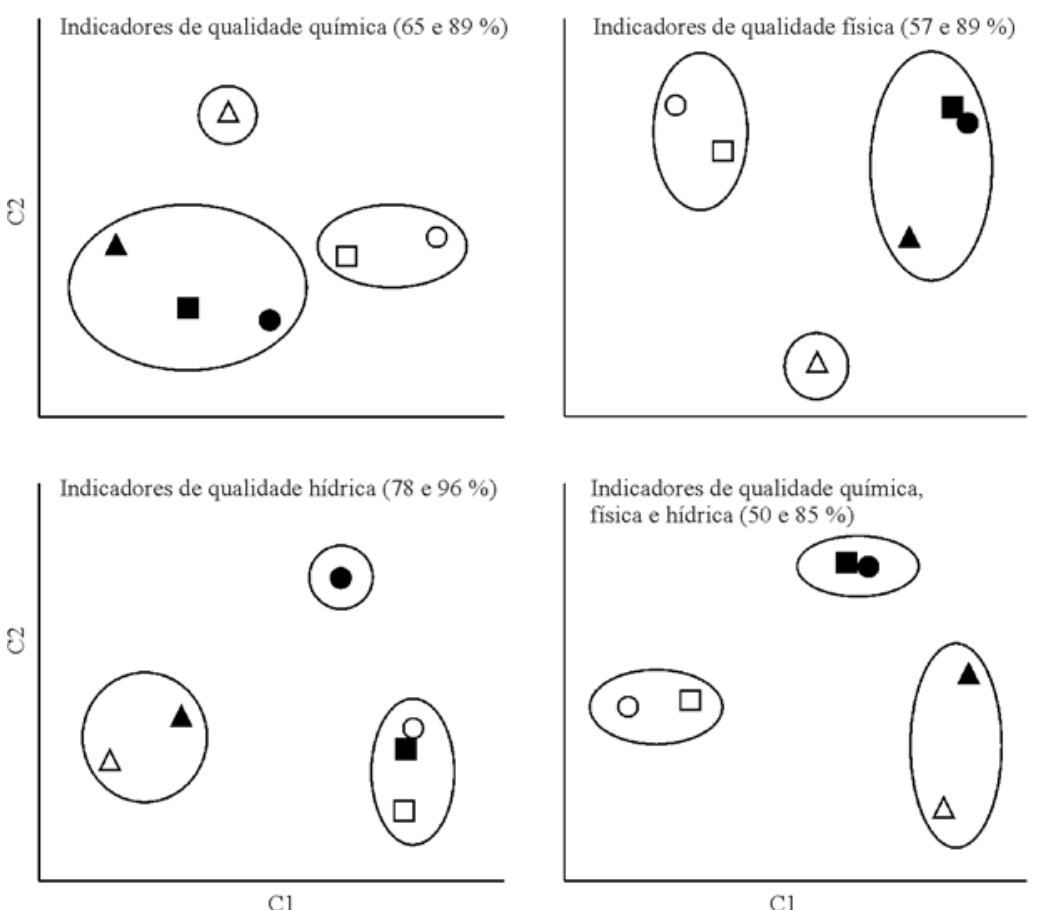

Figura 2. Dispersão dos indicadores de qualidade química, física e hídrica por posição de amostragem e camada de solo em relação aos dois primeiros componentes principais (C1 e C2) agrupados pelo método de Tocher (círculos e elipses), para um Latossolo Vermelho distrófico cultivado com laranjeira Valência. Legenda: $\triangle$ (projeção da copa da laranjeira; 0-0,20 m), $\Delta($ projeção da copa da laranjeira; 0,20-0,40 m), $\bigcirc$ (rodado da entrelinha; 0-0,20 m), ๑ (rodado da entrelinha, 0,20-0,40 m), $\square$ (centro da entrelinha; 0$0,20 \mathrm{~m}$ ) e $\square$ (centro da entrelinha; 0,20-0,40 m). Os valores percentuais dentro dos parênteses correspondem aos dois primeiros autovalores dos componentes principais.

e mata, nessa região, indicando maior degradação estrutural do solo na camada de $0-0,20 \mathrm{~m}$ no rodado da entrelinha. Esses autores verificaram que, paralelamente à degradação física desse solo, houve redução dos teores de carbono orgânico, observada também no rodado da entrelinha (Figura 1).

A densidade do solo na camada de $0-0,20 \mathrm{~m}$ foi de $1,64,1,70$ e $1,76 \mathrm{Mg} \mathrm{m}^{-3}$, respectivamente, na projeção da copa da laranjeira, no centro da entrelinha e no rodado da entrelinha (Figura 1). A variação da densidade do solo caracteriza a sua compactação pelo tráfego de máquinas no rodado da entrelinha, também verificada por Cintra et al. (1983), Sanches et al. (1999) e Fidalski (2004). A diferença de densidade do solo entre a projeção da copa da laranjeira e o centro da entrelinha sugere efeito residual do tráfego de máquinas no centro da entrelinha, remanescente da fase de formação do pomar, quando era necessária mais de uma passada do conjunto trator e implemento para os tratos culturais do pomar de citros. Em subsuperfície $(0,20-0,40 \mathrm{~m})$, os valores de densidade do solo são similares para projeção da copa da laranjeira, rodado da entrelinha e centro da entrelinha $(1,62$ $1,63 \mathrm{Mg} \mathrm{m}^{-3}$ ), comprovando que o tráfego das máquinas não influenciou a densidade do solo na camada de 0,20-0,40 m, discordando dos resultados obtidos por
Tavares Filho et al. (1999) e Soares et al. (2005). A semelhança dos valores de densidade do solo da camada de $0-0,20 \mathrm{~m}$ na projeção da copa da laranjeira com a camada de $0,20-0,40 \mathrm{~m}$, independentemente da posição de amostragem, evidencia a resiliência do solo com a suspensão do tráfego de máquinas na projeção da copa da laranjeira após a formação do pomar. Alternativamente, em vez de utilizar o revolvimento do solo nas entrelinhas de pomares de laranjeira, conforme Abercrombie \& Plessis (1995) e Souza et al. (2004), esse solo apresenta maior qualidade física com o aumento de carbono orgânico e redução da densidade quando mantido vegetado com a gramínea (Paspalum notatum), de acordo com os resultados experimentais de Fidalski (2004).

A microporosidade do solo mostrou gradiente crescente entre as posições de amostragem projeção da copa da laranjeira, rodado da entrelinha e centro da entrelinha ( $0-0,20$ e $0,20-0,40 \mathrm{~m})$ (Figura 1$)$. Por sua vez, na camada de $0-0,20 \mathrm{~m}$, a macroporosidade apresentou o maior valor na projeção da copa da laranjeira e relação inversa com a densidade do solo. Esse comportamento determinou a magnitude dos valores da $\theta / \mathrm{Pt}$ nos potenciais mátricos de $-0,001$ a $-0,010 \mathrm{MPa}$ (Figura 3). Na projeção da copa da laranjeira, não houve limitação de aeração no solo conferida pela 
porosidade com ar mínima de $0,10 \mathrm{~m}^{3} \mathrm{~m}^{-3}$ ou $10 \%$ (Grable \& Siemer, 1968). No rodado da entrelinha e centro da entrelinha, a porosidade de aeração foi menor do que $10 \%$ até o potencial mátrico de $-0,003 \mathrm{MPa}$, apontando para um possível comprometimento da oxigenação das raízes e trocas gasosas do solo sob condições de umidade elevada por períodos prolongados. De acordo com Soares et al. (2005), o valor mais elevado de porosidade do solo na camada de $0,20-0,40 \mathrm{~m}$ se deve ao maior teor de argila (Figura 1). A partir desse potencial mátrico, ocorreu suficiente porosidade com ar no solo, independentemente da posição e profundidade de amostragem.

Os indicadores de qualidade física do solo foram agrupados estatisticamente em três grupos, por meio da análise multivariada. Os autovalores dos dois primeiros componentes principais explicaram $89 \%$ da variação total (Figura 2). O grupo 1 foi constituído pela projeção da copa da laranjeira, pelo rodado da entrelinha e pelo centro da entrelinha $(0,20-0,40 \mathrm{~m})$; o grupo 2, pelo rodado da entrelinha e centro da entrelinha (0-0,20 m); e o grupo 3 , pela projeção da copa da laranjeira $(0-0,20 \mathrm{~m})$. Esses resultados mostram que os indicadores de qualidade física do solo não foram modificados na camada de $0,20-0,40 \mathrm{~m}$, mantendo um padrão homogêneo, independentemente da posição de amostragem de solo. O impacto do uso e do manejo desse solo com o tráfego de máquinas e equipamentos nas entrelinhas vegetadas não alterou a qualidade física do solo em subsuperfície, ao contrário das observações de Soares et al. (2005) em solo arenoso e de Tavares Filho et al. (1999) em solo argiloso.

Dentre os indicadores de qualidade hídrica do solo, $\theta c c / P t$ apresentou o valor médio de $0,66 \mathrm{~m}^{3} \mathrm{~m}^{-3}$ no rodado da entrelinha $(0,20-0,40 \mathrm{~m})$ (Figura 3 ), correspondendo ao valor ideal de qualidade física estabelecido por Reynolds et al. (2002). Valores menores que $0,66 \mathrm{~m}^{3} \mathrm{~m}^{-3}$ foram verificados na projeção da copa da laranjeira $(0,20$ e $0,20-0,40 \mathrm{~m})$, enquanto maiores valores ocorreram no rodado da entrelinha $(0-0,20 \mathrm{~m})$ e no centro da entrelinha $(0-0,20$ e $0,20-0,40 \mathrm{~m}$ ), os quais são indicativos de elevada retenção de água e, concomitantemente, menor capacidade de aeração do solo, constituindo-se numa limitação ao crescimento das raízes (Grable \& Siemer, 1968). Na camada de $0-0,20 \mathrm{~m}$ foram verificados maiores valores de densidade do solo e resistência do solo à penetração e reduzidos valores de macroporosidade (Figura 1), caracterizando a degradação física do solo observada por Cintra et al. (1983).

Os desequilíbrios da relação $\theta c c / \mathrm{Pt}$ na projeção da copa da laranjeira $\left(0-0,20\right.$ e $0,20-0,40 \mathrm{~m} ; 0,50-0,55 \mathrm{~m}^{3}$ $\left.\mathrm{m}^{-3}\right)$, no centro da entrelinha $(0-0,20 \mathrm{~m} \mathrm{e} 0,20-0,40 \mathrm{~m})$ e no rodado da entrelinha $(0-0,20 \mathrm{~m})$, expressos pelos valores de $0,78-0,83 \mathrm{~m}^{3} \mathrm{~m}^{-3}$, confirmam a descontinuidade vertical e horizontal do armazenamento de água e disponibilidade de ar para as laranjeiras (Figura 3). A espacialização vertical entre a projeção da copa da laranjeira e a entrelinha também foi descrita por Morgan et al. (2006), que constataram depleção da água do solo mediante maior densidade de raízes na camada de 0-0,10 m entre a projeção copa da laranjeira e a entrelinha, atribuída à presença de vegetação na entrelinha com predominância da gramínea (Paspalum notatum) e à ausência de vegetação na projeção da copa das laranjeiras.

A análise multivariada dos indicadores de qualidade hídrica do solo os agrupou estatisticamente em três grupos, com os autovalores dos dois primeiros componentes principais explicando $96 \%$ da variação total (Figura 2). O grupo 1 foi constituído pelo rodado da entrelinha $(0-0,20 \mathrm{~m})$ e centro da entrelinha (0-0,20 e $0,20-0,40 \mathrm{~m})$; o grupo 2 , pela projeção da copa da laranjeira $(0-0,20 \mathrm{~m}$ e $0,20-0,40 \mathrm{~m})$; e o

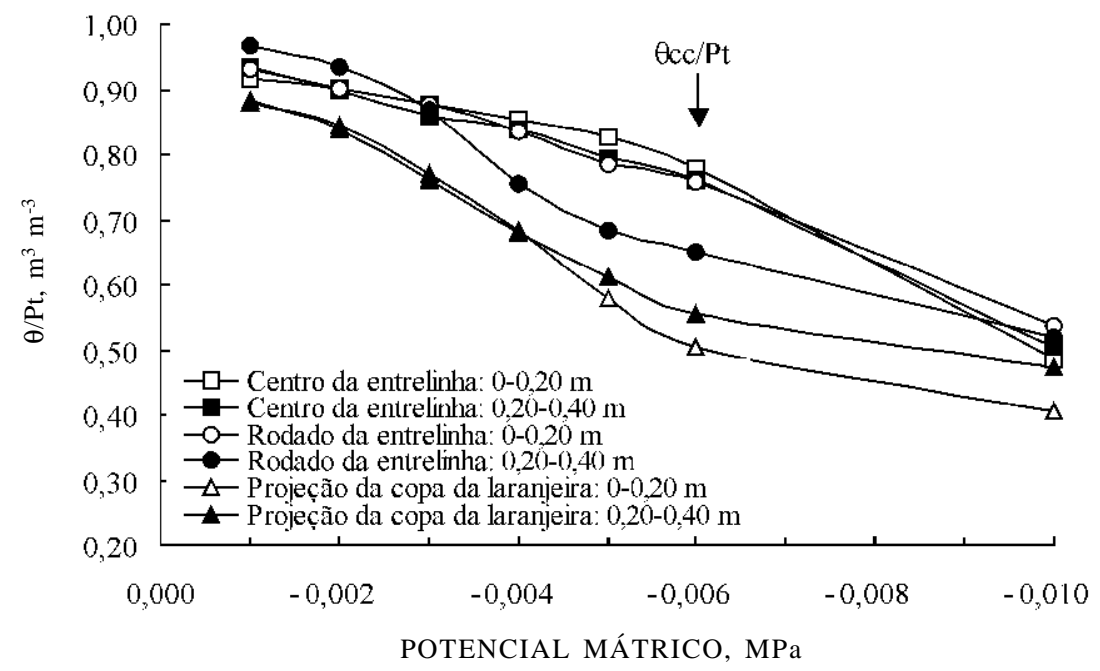

Figura 3. Saturação relativa do solo $(\theta / \mathrm{Pt})$ em diferentes potenciais mátricos de um Latossolo Vermelho distrófico cultivado com laranjeira Valência, nas posições de amostragem (copa da laranjeira, rodado da entrelinha e centro da entrelinha) e camadas $(0-0,20$ e $0,20-0,40 \mathrm{~m})$. $\theta$ cc/ $\mathrm{Pt}$ indicado pela seta corresponde ao indicador de qualidade física do solo proposto por Reynolds et al. (2002). 
grupo 3, pelo rodado da entrelinha $(0,20-0,40 \mathrm{~m})$. Esses resultados confirmam a descontinuidade vertical e horizontal da capacidade de armazenamento de água $(\theta c c / P t)$ entre a projeção da copa da laranjeira e as entrelinhas (rodado da entrelinha e centro da entrelinha); no rodado da entrelinha $(0,20-0,40 \mathrm{~m})$ ela é considerada diferente do restante das posições e camadas de amostragem, justificado pela condição ideal de $\theta c c / P t$, conforme Reynolds et al. (2002), em que a disponibilidade de água e ar é favorável ao crescimento das raízes. Lima et al. (2005) verificaram maior diversidade de poros relacionados com os processos de degradação da estrutura do solo em pomar de laranjeira, os quais foram mais sensíveis do que a densidade do solo para identificação da sua compactação. Neste estudo, o indicador $\theta c c / P t$ mostrou maior sensibilidade em diferenciar a qualidade de solo na camada de 0,20-0,40 m do que a própria densidade e porosidade do solo (Figura 1), confirmando a capacidade de suporte de carga desse solo pelo tráfego de máquinas localizado no rodado da entrelinha do pomar, sem comprometimento da qualidade do solo em subsuperfície.

A análise multivariada conjunta dos indicadores químicos, físicos e hídricos do solo distinguiu três grupos, com os autovalores dos dois primeiros componentes principais explicando $85 \%$ da variação total (Figura 2). O grupo 1 foi constituído pela projeção da copa da laranjeira $(0-0,20$ e 0,20-0,40 m); o grupo 2, pelo rodado da entrelinha e centro da entrelinha $(0-0,20 \mathrm{~m})$; e o grupo 3 , pelo rodado da entrelinha e centro da entrelinha $(0,20-0,40 \mathrm{~m})$. Os resultados vêm corroborar o estudo realizado por Auler et al. (2004), ao terem verificado no período de seis safras agrícolas redução significativa de $21 \%$ da produção de frutos da laranjeira Valência (portaenxerto limoeiro Cravo), devido à restrição do preparo convencional do solo realizado em faixa de $2 \mathrm{~m}$ de largura destinada à linha das plantas, com a manutenção da gramínea (Paspalum notatum) na entrelinha não-revolvida de $5 \mathrm{~m}$, remanescente de uma área de pastagem.

A qualidade química e física do solo no pomar de laranjeira foi agrupada vertical e horizontalmente em zonas homogêneas (projeção da copa da laranjeira, rodado da entrelinha e centro da entrelinha), mas antagônicas (Figura 2), cujo controle é determinado pelo tráfego das máquinas (rodado da entrelinha e centro da entrelinha) para as ações de manejo do pomar e pela aplicação localizada de fertilizantes na projeção da copa da laranjeira. As posições de amostragem rodado da entrelinha e centro da entrelinha $(0-0,20 \mathrm{~m})$ constituíram o grupo com qualidade de solo mais distinto em relação às demais camadas e posições de amostragem avaliadas, apresentando desequilíbrio entre a qualidade física, hídrica e química do solo. Provavelmente, as raízes das laranjeiras, ao encontrarem limitações da qualidade física e hídrica para o seu desenvolvimento da projeção da copa da laranjeira em direção ao centro da entrelinha
(0-0,20 m), poderiam seguir a direção mais favorável ao seu desenvolvimento no rodado da entrelinha (0,20-0,40 m).

O presente estudo, envolvendo as análises multivariadas dos indicadores de qualidade química, física e hídrica do solo, mostrou o impedimento físico superficial $(0-0,20 \mathrm{~m})$ para o desenvolvimento radicular dos citros no rodado da entrelinha. Esses resultados não justificariam que fosse realizado o revolvimento superficial desse solo para descompactálo no rodado da entrelinha, visto a ineficiência da escarificação mecânica na produção da laranjeira (Bordin et al., 2005). Os resultados positivos da descompactação com a subsolagem do solo na entrelinha sobre a produção de frutos de pomares de laranjeira foram obtidos por Abercrombie \& Plessis (1995) e Souza et al. (2004), prática precedida de um diagnóstico que mostrava camada de solo compactado ou camada de solo coeso em subsuperfície. O manejo mais apropriado para o agroecossistema citrícola em solos da Formação Caiuá é a manutenção de plantas de cobertura permanente com gramínea na entrelinha do pomar (Fidalski, 2004; Fidalski et al., 2006), para assegurar melhor qualidade física e hídrica do solo e, por conseguinte, aumentar a disponibilidade dos nutrientes para as laranjeiras (Fidalski \& Stenzel, 2006).

\section{CONCLUSÕES}

1. A qualidade do solo apresentou espacialização heterogênea entre os indicadores de qualidade física, química e hídrica do solo, resultante das ações de manejo do pomar de laranjeira.

2. A integração dos indicadores de qualidade física, química e hídrica do solo caracterizou a espacialização vertical da qualidade do solo $(0-0,40 \mathrm{~m})$ na projeção da copa da laranjeira e a espacialização vertical e horizontal $(0-0,20$ e $0,20-0,40 \mathrm{~m})$ no rodado da entrelinha e centro da entrelinha.

3 . No rodado da entrelinha $(0-0,20 \mathrm{~m})$ ocorreu a maior restrição física e hídrica, associada à melhor condição química do solo para as laranjeiras.

\section{LITERATURA CITADA}

ABERCROMBIE, R.A. \& PLESSIS, S.F.D. The effect of alleviating soil compaction on yield and fruit size in an established Navel orange orchard. J. South. Africa Soc. Hort. Sci., 5:85-89, 1995.

AULER, P.A.M.; FIDALSKI J.; PAVAN, M.A.; GOMES, J.C. \& JACOMINO, A.P. Sistema de preparo do solo, calagem e porta-enxertos para a produção de laranja Valência na região noroeste do Paraná. In: CONGRESSO BRASILEIRO DE FRUTICULTURA, 18., Florianópolis, 2004. Anais. Florianópolis, Sociedade Brasileira de Fruticultura, 2004. CD-ROM. 
BORDIN, I.; NEVES, C.S.V.J.; AIDA, F,T.; SOUZA, W.R.; DAVOGLIO JUNIOR, A.C.; FURLANETO, T.L.R. \& TAVARES FILHO, J. Sistema radicular de plantas cítricas e atributos físicos do solo em um Latossolo argiloso submetido à escarificação. Ci. Rural, 35:820-825, 2005.

CARDOSO, A.; POTTER, R.O. \& DEDECEK, R.A. Estudo comparativo da degradação de solos pelo uso agrícola no noroeste do Paraná. Pesq. Agropec. Bras., 27:349-353, 1992.

CINTRA, F.L.D.; COELHO, Y.S.; CUNHA SOBRINHO, A.P. \& PASSOS, O.S. Caracterização física do solo submetido a práticas de manejo em pomar de laranja "Baianinha". Pesq. Agropec. Bras., 18:173-179, 1983.

CRUZ, A.C.R.; LIBARDI, P.L.; CARVALHO, L.A. \& ROCHA, G.C. Balanço de água no volume de solo explorado pelo sistema radicular de uma planta de citros. R. Bras. Ci. Solo, 29:1-10, 2005.

CRUZ, C.D. Programa GENES: versão windows. Viçosa, MG, Editora UFV, 2001. 642p. (Versão 2005.0.0).

CRUZ, C.D.; REGAZZI, A.J. \& CARNEIRO, P.C.S. Modelos biométricos aplicados ao melhoramento genético. 3.ed. Viçosa, MG, Universidade Federal de Viçosa, 2004. 480p.

DANE, J.H. \& HOPMANS, J.W. Pressure plate extractor. In: DANE, J.H. \& TOPP, C., eds. Methods of soil analysis: physical methods. Madison, Soil Science Society of America, 2002. v.4, p.688-690.

DRAGHI, L.; JORAJURÍA, D.; CERRISOLA, C. \& DELGADO, L.M. Resistência específica do solo de um pomar frutícola relacionada ao manejo entrelinhas e intensidade de tráfego. Eng. Agric., 25:385-394, 2005.

EMPRESA BRASILEIRA DE PESQUISA AGROPECUÁRIA . EMBRAPA. Manual de métodos de análises de solo. 2.ed. Rio de Janeiro, Centro Nacional de Pesquisa de Solos, 1997. 212p. (Embrap/CNPS, Documentos, 1)

EMPRESA BRASILEIRA DE PESQUISA AGROPECUÁRIA EMBRAPA. Sistema brasileiro de classificação de solos. EMBRAPA Produção de informação; Rio de Janeiro: Embrapa Solos, 1999. 412p.

FERRERO, A.; USOWICZ, B. \& LIPIEC, J. Effects of troctor traffic on spatial variability of soil strength and water content in grass covered and cultivated sloping vineyard. Soil Till. Res., 84:127-138, 2005.

FIDALSKI, J. Propriedades físico-hídricas de um Argissolo Vermelho distrófico latossólico em diferentes sistemas de manejo das entrelinhas de citros. Maringá, Universidade Estadual de Maringá, 2004. 62p. (Tese de Mestrado)

FIDALSKI, J. \& AULER, P.A.M. Levantamento nutricional de pomares de laranja no noroeste do Paraná. Arq. Biol. Tecnol., 40:443-451, 1997.

FIDALSKI, J. \& STENZEL, N.M.C. Nutrição e produção da laranjeira "Folha Murcha" em porta-enxertos e plantas de cobertura permanente na entrelinha. Ci. Rural, 36:807. 813, 2006.

FIDALSKI, J. \& TORMENA, C.A. Dinâmica da calagem superficial em um Latossolo Vermelho distrófico. R. Bras. Ci. Solo, 29:235-247, 2005.
FIDALSKI, J.; MARUR, C.J.; AULER, P.A.M. \& TORMENA, C.A. Produção de laranja com plantas de cobertura permanente na entrelinha. Pesq. Agropec. Bras., 41:927935, 2006.

FIDALSKI, J.; PAVAN, M.A.; AULER, P.A.M. \& JACOMINO, A.P. Produção de frutos de laranjeira Pêra e teores de nutrientes nas folhas e no solo, em Latossolo VermelhoEscuro do noroeste do Paraná. R. Bras. Ci. Solo, 23:273279, 1999.

GRABLE, A.R. \& SIEMER, E.G. Effects of bulk density, aggregate size, and soil water suction on oxygen diffusion, redox potentials and elongation of corn roots. Soil Sci. Soc. Am. J., 32:180-186, 1968.

GROSSMAN, R.B. \& REINSCH, T.G. Bulk density and linear extensibility. In: DANE, J.H. \& TOPP, C., eds. Methods of soil analysis: physical methods. Madison, Soil Science Society of America, 2002. v4. p.201-228.

GRUPO PAULISTA DE ADUBAÇÃO E CALAGEM PARA CITROS. Recomendações de adubação e calagem para citros no Estado de São Paulo. Laranja (Edição Especial): 1-27, 1994.

INSTITUTO AGRONÔMICO DO PARANÁ - IAPAR. Cartas climáticas do Paraná. versão 1.0. Londrina, 2000. CDROM.

LIMA, H.V.; LIMA, C.L.R.; LEÃO, T.P.; COOPER, M.; SILVA, A.P. \& ROMERO, R.E. Tráfego de máquinas agrícolas e alterações de bioporos em área sob pomar de laranja. R. Bras. Ci. Solo, 29:677-684, 2005.

MALAVOLTA, E. \& VIOLANTE NETTO, A. Nutrição mineral, calagem, gessagem e adubação dos citros. Piracicaba, POTAFOS, 1989. 153p.

MORGAN, K.T.; OBREZA, T.A.; SCHOLBERG, J.M.S.; PARSONS, L.R. \& WHCATON, T.A. Citrus water uptake dynamics on a sandy Florida Entisol. Soil Sci. Soc. Am. J., 70:90-97, 2006.

NEVES, C.S.V.J.; DECHEN, A.R.; FELLER, C.; SAAB, O.J.G.A. \& PIEDADE, S.M.S. Efeito do manejo do solo no sistema radicular de tangerineira "Poncã" enxertada sobre limoeiro Cravo em Latossolo Roxo. R. Bras. Frutic., 20:246$253,1998$.

NEVES, C.S.V.J.; MURATA, I.M.; STENZEL, N.M.C.; MEDINA, C.C.; BORGES, A.V.; OKUMOTO, S.H.; LEE, R.H.C. \& KANAI, H.T. Root distribution of rootstocks for 'Tahiti' lime. Sci. Agric., 61:94-99, 2004.

PAVAN, M.A. \& JACOMINO, A.P. Root growth and nutrient contents of citrus rootstocks in an acid soil with varied pH. Ci. Cult., 50:56-59, 1998.

QUAGGIO, J.A. Análise de solo para citros: Métodos e critérios para a interpretação de resultados. In: SEMINÁRIO INTERNACIONAL DE CITROS, 4., Bebedouro, 1996. Anais. Campinas, Fundação Cargill, 1996. p.95-113.

QUAGGIO, J.A.; CANTARELLA, H. \& RAIJ, B. van. Phosphorus and potassium soil test and nitrogen leaf analysis as a base for citrus fertilization. Nutr. Cycl. Agroecosyst., 52:67-74, 1998. 
QUAGGIO, J.A.; TEÓFILO SOBRINHO, J. \& DECHEN, A.R. Response to liming of "Valencia" orange tree on Rangpur Lime: effects of soil acidity on plant growth and yield. In: INTERNATIONAL CITRUS CONGRESS, 7., Acireale, 1992. Proceedings. Acireale, Internatinal Society Citriculture, 1992.v.2, p.628-632.

REICHARDT, K. Capacidade de campo. R. Bras. Ci. Solo, 12:211-216, 1988.

REYNOLDS, W.D.; BOWMAN, B.T.; DRURY, C.F.; TAN, C.S. \& LU, X. Indicators of good soil physical quality: density and storage parameters. Geoderma, 110:131-146, 2002.

ROMANO, N.; HOPMANS, J.W. \& DANE, J.H. Suction table. In: DANE, J.H. \& TOPP, C., eds. Methods of soil analysis: physical methods. Madison, Soil Science Society of America, 2002. v.4, p.692-698.

SANCHES, A.C.; SILVA, A.P.; TORMENA, C.A. \& RIGOLIN, A.T. Impacto do cultivo de citros em propriedades químicas, densidade do solo e atividade microbiana de um Podzólico Vermelho-Amarelo. R. Bras. Ci. Solo, 23:91-99, 1999.

SAS INSTITUTE. SAS/STAT user's guide. Version 8.2. Cary, 2001. 943p.
SOARES, J.L.N.; ESPÍNDOLA, C.R. \& CASTRO, S.S. Alteração física e morfológica em solos cultivados sob sistema tradicional de manejo. R. Bras. Ci. Solo, 29:1005-1014, 2005.

SOUZA, L.D.; SOUZA, L.S. \& LEDO, C.A.S. Disponibilidade de água em pomar de citros submetido a poda e subsolagem em Latossolo Amarelo dos Tabuleiros Costeiros. R. Bras. Frutic., 26:69-73, 2004.

TAVARES FILHO, J.; RALISCH, R.; GUIMARÃES, M.F.; MEDINA, C.C.; BALBINO, L.C. \& NEVES, C.S.V.J. Método do perfil cultural para avaliação do estado físico de solos em condições tropicais. R. Bras. Ci. Solo, 23:393399, 1999.

THEODORO, V.C.A.; ALVARENGA, M.I.N.; GUIMARÃES, R.J. \& SOUZA, C.A.S. Alterações químicas em solo submetido a diferentes formas de manejo do cafeeiro. R. Bras. Ci. Solo, 27:1039-1047, 2003.

TORMENA, C.A.; SILVA, A.P. \& LIBARDI, P.L. Caracterização do intervalo hídrico ótimo de um Latossolo Roxo sob plantio direto. R. Bras. Ci. Solo, 22:573-581, 1998. 